\title{
Alumina-based composites reinforced with silver particles
}

\author{
Enrique Rocha-Rangel ${ }^{1, ~}{ }^{*}$, Elizabeth Refugio-García ${ }^{2}$, José Miranda-Hernández $^{3}$, \\ Eduardo Terres-Rojas ${ }^{4}$ \\ ${ }^{1}$ Universidad Politécnica de Victoria, 87138, México \\ ${ }^{2}$ Departamento de Materiales, Universidad Autónoma Metropolitana, 02200, México \\ ${ }^{3}$ Universidad Autónoma del Estado de México (UAEM-Valle de México), 54500, México \\ ${ }^{4}$ Laboratorio de Microscopía Electrónica de Ultra Alta Resolución, IMP, 07730, México
}

\section{Email address:}

erochar@upv.edu.mx (E. Rocha-Rangel)

\section{To cite this article:}

Enrique Rocha-Rangel, Elizabeth Refugio-García, José Miranda-Hernández, Eduardo Terres-Rojas. Alumina-Based Composites Reinforced with Silver Particles. Advances in Materials. Vol. 2, No. 6, 2013, pp. 62-65. doi: 10.11648/j.am.20130206.11

\begin{abstract}
Al}_{2} \mathrm{O}_{3} / \mathrm{Ag}$ composite ceramics were fabricated by the use of mechanical milling and pressureless sintering. $\mathrm{Al}_{2} \mathrm{O}_{3}+10$ wt. $\%$ Ag were mixed and milled during $12 \mathrm{~h}$ at $300 \mathrm{rpm}$ in a horizontal mill, then with the powder mixture it was conformed cylindrical samples by uniaxial pressing using $300 \mathrm{MPa}$. The pressed samples were sintered during $1 \mathrm{~h}$ in an electrical furnace at 1300,1400 and $1500^{\circ} \mathrm{C}$ respectively. Sinter was performed using an argon atmosphere inside the furnace in order to inhibit silver oxidation. XRD results established that silver retains its crystalline structure. On the other hand, density of samples is better with increments in temperature. However, the final relative density is small and about of 91\%. Scanning electron microscopy observations show alumina's microstructure with very fine and homogeneous distributions of silver particles. Increments in sintering temperature are reflected as enhancements of the density and consequently of the fracture toughness of the $\mathrm{Al}_{2} \mathrm{O}_{3} / \mathrm{Ag}$ composite ceramics.
\end{abstract}

Keywords: $\mathrm{Al}_{2} \mathrm{O}_{3} / \mathrm{Ag}$ Composites, Fracture Toughness, Pressureless Sintering, Metallic Reinforcement

\section{Introduction}

Alumina $\left(\mathrm{Al}_{2} \mathrm{O}_{3}\right)$ ceramic presents good mechanical properties such as: high hardness, high compressive strength, good chemical and thermal stability. However, its applications as structural material have been limited principally by its low fracture toughness. $\mathrm{Al}_{2} \mathrm{O}_{3}$ ceramics can be toughened with the incorporation of fine metallic particles [1], for this reason it has been prepared successfully some $\mathrm{Al}_{2} \mathrm{O}_{3}$-systems by different techniques such as: pressure-assisted thermal explosion [2], slip casting [3], metal infiltration [4-6], sintering high pressing [7], Chemical deposition [8], self-propagation high temperature synthesis [9] and reaction synthesized [10]. Nevertheless, most of these processes are costly and they are very complex in their procedures and control. From these studies authors have been documented that fracture toughness of a ceramic-metal composite can be controlled by the volume fraction of metallic phase as well as the size of metal particles and its homogeneous distribution in the ceramic matrix. With these considerations in mind, simple and cheaper processes were developed for the production of ceramic-metal composites [11]. High-energy ball milling combined with pressureless sintering can be a substitute low-cost method for the production of ceramic-metal composite. The use of silver, that certainly is an expensive metal, is explained by the fact of the big ductility that possesses this metal, being this property an important consideration that several authors [12-16] have suggested as a characteristic significant than has to has a reinforced material of ceramics. For that, it has been propose that one of the main reinforced mechanisms of ceramics by metals is the crack bridging due to ductile metallic ligaments. At this date, there is not knowing of studies over reinforced of ceramics by silver.

The aim of this study is to synthesize $\mathrm{Al}_{2} \mathrm{O}_{3}$-based composites reinforced with $10 \mathrm{wt} \%$ silver using powder techniques in order to determine the effect of silver on the fracture toughness of the alumina-matrix. 


\section{Experimental}

Starting materials were: $\mathrm{Al}_{2} \mathrm{O}_{3}$ powder $(99.9 \%, 1 \mu \mathrm{m}$, Sigma, USA) and silver powder (99.9 \%, 1-2 $\mu \mathrm{m}$, Aldrich, USA). Final silver content in the produced composites was $10 \mathrm{wt} . \%$. Powder blends of $20 \mathrm{~g}$ were prepared in a ball mill with $\mathrm{ZrO}_{2}$ media, the rotation speed of the mill was of 300 rpm, and studied milling time was $12 \mathrm{~h}$. With the milled powder mixture, green cylindrical compacts $2 \mathrm{~cm}$ diameter and $0.2 \mathrm{~cm}$ thickness were fabricated by uniaxial pressing, using $300 \mathrm{MPa}$ pressure. Then pressureless sinter in an electrical furnace was performed under $10 \mathrm{~cm}^{3} / \mathrm{min}$ argon flux, at three different temperatures $(1300,1400$ and $1500{ }^{\circ} \mathrm{C}$ ) during $1 \mathrm{~h}$. The microstructure was observed by scanning electron microscopy (SEM) equipped with an analyzer by energy dispersive spectroscopy (EDS). Fracture toughness was estimated by the fracture indentation method [17], (in all cases twelve independent measurements per value were carrying out).

\section{Results and Discussion}

\subsection{Density}

Results of the density measurements in different samples are shown in Fig.1. As shown in this figure, is clear the tendency to density of the material, in the way that the sintered temperature is higher. This is because at higher temperatures the binding of the particles and the consequent closing of pores is provided by the migration of atoms due to the high activation energy reached at these temperatures. Shrinkage of different samples determined by direct measurements of the same before and after sintering was: 6 , 12 and $19.34 \%$ for sintered samples at $1300,1400 \mathrm{y} 1500^{\circ} \mathrm{C}$ respectively. What helps corroborate the reason because densification is increased at elevated temperatures.

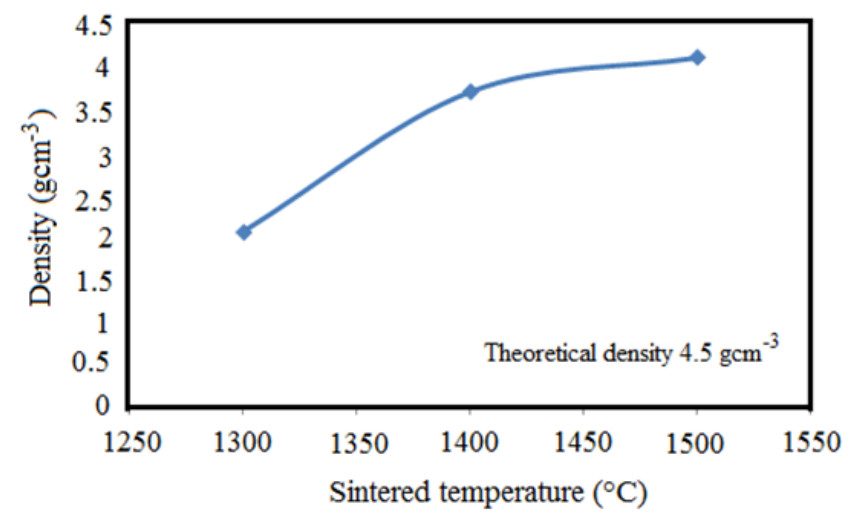

Figure 1. Sample's density as a function of sintered temperature.

\subsection{X-Ray Diffraction}

X-ray diffraction patterns of the powder mixture after grinding and sample sintered at $1500^{\circ} \mathrm{C}$ during 1 hour are shown in Fig. 2. In the corresponding spectrum to the mixture of powders, it is revealed the presence of the two original components of the mixture; alumina and silver; in this same pattern it is not observed the presence of any diffraction peak that would designate the presence of any other compound which indicated contamination of the sample during the milling step. Regarding the pattern corresponding to the sample sintered, they have clearly defined the diffraction peaks of $\alpha$-alumina phase and metallic silver. Comparing both diffraction patterns of fig. 2 , is that the main diffraction peak of the silver that is the one located at $37.4^{\circ}$ two theta degrees, slightly reduced in intensity after the sample was sintered, thinking allowing some oxidation of the silver. However, in the diffraction pattern of the sintered sample it is not showing any diffraction peak indicating the presence of a silver oxide, so it is discarded the oxidation of the silver during the sintered step.



Figure 2. X-ray diffraction patterns of powders mixture after milling and sintered sample at $1500^{\circ} \mathrm{C}$, during $1 \mathrm{~h}$.

\subsection{Microstructure}

Typical microstructures of the sintered samples at 1300 , 1400 y $1500^{\circ} \mathrm{C}$ are presented in Fig. 3. As can be seen in these figures, is that with increments of the sintered temperature, samples tend to densify, because there is a decrease in the size and number of pores in these. This situation confirms the results of the density measurements made by the Archimedes method. Another important observation is that in all cases they have homogeneous microstructures, predominantly with equiaxed grains, but equally there are some deformed grains. The grain size increases in agreement with the increment of temperature. All these grains are spoken correspond to the ceramic phase of the composite material, it means is the alumina matrix. The silver particles are the very fine and bright dots observed in intergranular regions of the matrix. To confirm the presence of silver in these microstructures, energy dispersive spectroscopy (EDS) analyzes were performed on clear particles of the samples, A typical EDS spectrum is showing in fig. 3. In this spectrum it is observed that the principal component where the analyses were performed is silver. 


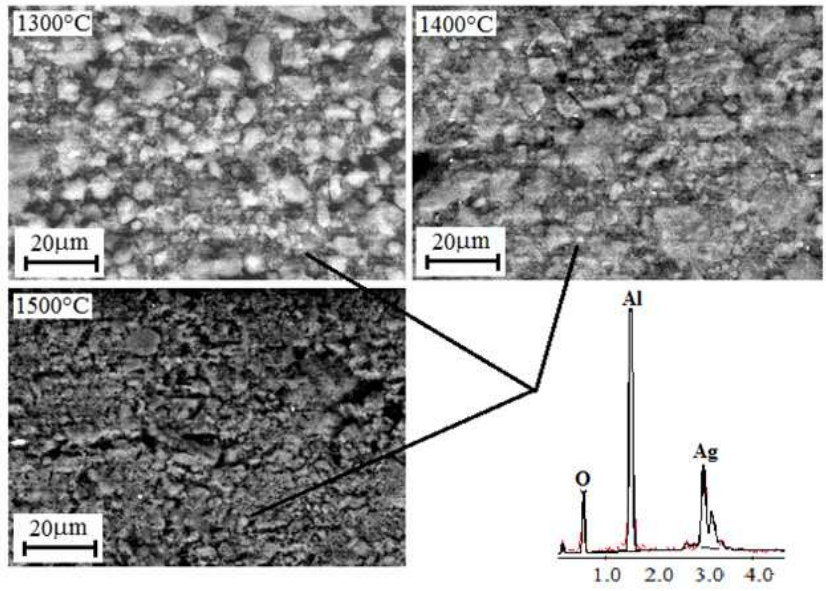

Figure 3. Microstructure of samples sintered at 1300,1400 and $1500^{\circ} \mathrm{C}$. Typical EDS spectrum of analysis performed in white dots of different samples.

\subsection{Mechanical Properties}

The results of the measurement of microhardness and fracture toughness performed in the samples sintered during $1 \mathrm{~h}$ at different temperatures are presented in Fig. 4. In both curves it is observed that mutually the microhardness and fracture toughness of alumina-silver composite are improved as the sintered temperature increases, this is a consequence of have a good densified body. The microhardness value reported in the literature [18] for pure alumina is $1175 \mathrm{HV}$, value significantly higher than that achieved by the compounds manufactured here, this difference is due to the lower degree of densification achieved in our composites. With respect to the fracture toughness the value reported in the literature for alumina is 3.2 $\mathrm{MPa} \cdot \mathrm{m}^{1 / 2}$ [13], while the value of this same property obtained by composites made here, has achieved in the best case $4.3 \mathrm{MPa} \cdot \mathrm{m}^{1 / 2}$, equivalent value to a $34 \%$ higher. This improvement in fracture toughness is attributable to the incorporation into the ceramic matrix of a metal with high ductility such as silver. Several authors [1, 11, 13] have commented that the toughening mechanism in $\mathrm{Al}_{2} \mathrm{O}_{3} /$ metals composites is due to plastic deformation of the metallic phase, which forms crack-bridging ligaments. Thus it is illustrated the significant effect on the fracture toughness of alumina the incorporation therein of small amounts of a ductile metal as silver. However, it is important to consider that this improvement of the fracture toughness can be enhanced even if bodies can be manufactured with higher densifications. On the other hand, it would be interesting to conduct a study varying silver content in the matrix, as it is very likely get very different behaviors with other silver contents.

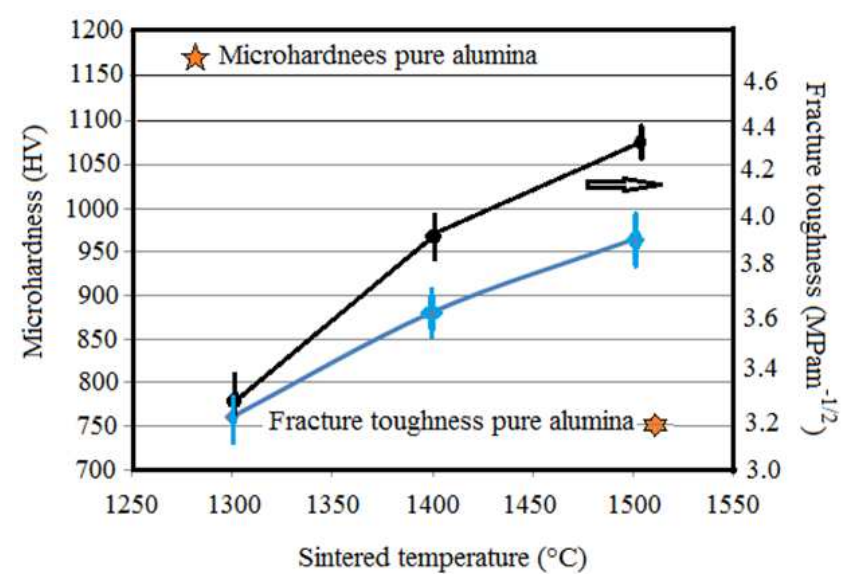

Figure 4. Microhardness and fracture toughness of samples sintered as a function of sintered temperature.

\section{Conclusions}

$\checkmark \quad \mathrm{Al}_{2} \mathrm{O}_{3}$-based composites can effectively be produced by inducing fine dispersions of silver particles, through a combination of experimental techniques, such as; mechanical milling and pressureless sintering (in an argon-atmosphere).

$\checkmark \quad$ The refined and homogeneous incorporation of silver in a ceramic matrix $\left(\mathrm{Al}_{2} \mathrm{O}_{3}\right)$ improves its fracture toughness. Alternatively, increments in sintering temperature are reflected as enhancements of the density and consequently of the fracture toughness of the same one.

$\checkmark$ From the fracture toughness measurements and microstructure observations, it can be commented that the toughening mechanism in $\mathrm{Al}_{2} \mathrm{O}_{3} / \mathrm{Ag}$ composites is due to plastic deformation of the metallic phase, which forms crack-bridging ligaments.

\section{Acknowledgements}

The microscopy laboratory facility given by IMP and processing laboratories of UAM-A, UAEM and UPV is appreciated. In addition, ERR are grateful to CONACyT by the support given to carry out this work through Project 132406.

\section{References}

[1] O.L. Ighodaro and O.I. Okoli, International Journal of Applied Ceramics Technology (2008)313-323.

[2] N. Travitzkya, I. Gotmanb and N. Claussena, Materials Letters 57(2003)3422-3426.

[3] M. Szafran, K. Konopka, E. Bobryk and K.J. Kurzydłowski, Journal of the European Ceramic Society 27(2007)651-654.

[4] S. Avraham, P. Beyer, R. Janssen, N. Claussen and W.D. Kaplan, Journal of the European Ceramic Society 26(2006)2719-2726. 
[5] P. Agrawal and C.T. Sun, Composites Science and Technology 64(2004)1167-1178.

[6] A. Matterna, B. Huchlerb, D. Staudeneckerb, R. Oberackera, A. Nagelb and M.J. Hoffmanna, Journal of the European Ceramic Society 24(2004)3399-3408.

[7] K. Konopka, J.J. Bucki, S. Gierlotka, W. Zielin'ski, and K.J. Kurzyydowski, Materials Characterization 56(2006)394-398.

[8] J. Li, J. Sun and L. Huang, Materials Science and Engineering A323(2002)17-20.

[9] D. Horvitza, I. Gotmana, E.Y. Gutmanasa and N. Claussen, Journal of the European Ceramic Society 22(2002)947-954.

[10] A. Taotao, Chinese Journal of Aeronautics 21(2008)559-564.

[11] E. Rocha-Rangel, E. Refugio-García, J. G. Miranda-Hernández and E. Terrés-Rojas, Journal of Ceramic Processing Research, 10[6](2009)744-747.
[12] J. G. Miranda-Hernández, Master Thesis, Universidad Autonoma Metropolitana, Mexico (2006).

[13] J. M. Miranda, S. Moreno, B. Soto and E. Rocha, Journal of Ceramic Processing Research, 7[4](2006)311-314.

[14] V. Mercedes, Doctoral Thesis, Universidad Autónoma de Madrid, Instituto de Ciencia de Materiales de Madrid, Spain (2003).

[15] A. Feder, I. Llanes and M. Anglada, Bol. Soc. Esp. Ceram. 43(2004)47-52.

[16] R. Günther, T. Klassen, B. Dickau, F. Gärtner, A. Bartels and R. Bormann, Journal of American Ceramic Society, 84(2001)1509-1513

[17] A.G. Evans and E.A. Charles, Journal of the American Ceramic Society, 59(1976)371-372.

[18] J.F. Shackelford and R.H. Doremus, Ceramic and Glass Materials: Structure, Properties and Processing. Springer (2010). 